\title{
CONTRIBUTION OF ECOLOGICAL DESIGN TO CRITICAL REGIONALISM: ANALYSING SUSTAINABILITY EFFECTIVENESS IN VERNACULAR URBAN BUILDING
}

\author{
Stephen T.F. Poon \\ Asia Pacific University of Technology \& Innovation, Malaysia
}

KEY WORDS: Sustainable Design, Ecological Architecture, Passive Design Strategies, Vernacular, Place-Making

\begin{abstract}
:
Environmentalism as the overall concept of ecological architecture is defined as the inter-relations between people, and how built forms affect the surroundings through design, reflecting the impact of technology, human principles of living with nature, and of social connections in communities. Modern ecological designs have smart solutions in planning climatic zones, with optimised natural lighting to lower energy use, and reduce wastage. Passive thermal comfort methods and spatial alignment of buildings to sun orientation have brought the ideals of organic architecture full circle since the "sparse and scarce" principles of technological design limitations guided vernacular urbanism over time. Today's modern buildings, abstracted from mass-produced designs, are shaped to trends and tastes, bringing attention to the artificial materiality of architectural forms and the hidden costs of innovations. To understand the relevance of sustainable strategies in developing critical regionalism, this paper reviews the scope of ecological architecture principles application for temperate climates, and examines the viability of strategies as passive cooling, thermal comfort and greenery-based ventilation. Through case study discussions of two Malaysian eco-architectural designers, Ken Yeang and Kevin Mark Low, it will also be argued that the spirit of nationalism and cultural regionalism can be integrated effectively into urban built forms.
\end{abstract}

\section{INTRODUCTION} "We shape our buildings; thereafter they shape us." Winston
Churchill

Before modernism, conventional architectural design enjoyed closer relationships to the specificities of location and topography (Pearce and Yong, 2012). Buildings in vernacular styles were perceived important for their role as place-making representations of social, cultural and national identities (Day, 2002). From eco-psychological perspectives, vernacular approaches were more than key inspiration of good architectural design. They represented the philosophy of architecture being associated with national attainments.

Architects, urban planners and designers built to define nationalist identities. They thus signified the larger aspirations for socioeconomic development, of good management of natural resources and land use, without sacrificing heritage preservation (Preston, 2007). This view was preferred to the organic notion that architecture represents human intimacy with natural terrains and landscapes, of devising and strengthening social connections with local communities (Wines, 2000). The spatial living experience of buildings, as anthroposophist Christopher Day (2007) stated, was as crucial as its appearance.

For this paper, the purpose of research is to critically analyse current issues that have arisen as contributed by the problem of mass urban socioeconomic development. It is argued that while contemporary architectural designs represent different approaches to reinventing built environments, built practices could leverage on ecological technologies to accentuate vernacular place-making by emphasising sustainable and creative architecture. This research is relevant to architectural design practice as it raises questions to further the current scopes of sustainability development in built strategies specifically for Asian environments, such as: How do Asian buildings embrace ecological architecture principles for enhanced urban place-making? How could the spirit of nationalism and cultural regionalism be integrated into urban eco-architectural principles?

\section{LITERATURE REVIEW}

The focus for architectural development in post-World War I Europe and North America was on designing and synthesising their national identities, effectively rationalising how they were to play universal leadership roles in expanding world cultures (Frampton, 1983). In the $20^{\text {th }}$-century, as architectural knowledge increased, the new cultural idealism became the new measure of built design achievement: shared activity spaces meant for social conversations, interaction, work and leisure (Day, 2007: pp.143-155).

Projects are viewed as markers of critical regionalism when they cultivate a strong and respectful sense of place (Frampton, 1983). Buildings signified the "unspoken values" of society, assuring architect's posterity by their achievements in creating these sites of precise nationalist sentiments (Day, 2014: p.69). Today's built environment experiences are an outgrowth of a broader urbanist movement. Leading European architecture professors such as Mat Santamouris at the University of Athens and colleagues, for instance, conduct field studies into bioclimatic architectural principles and applications, while lecturing, supervising projects and training urban planners in energy efficiency, thermal comfort and bioclimatic design of buildings and open spaces (Gaitani et al, 2007).

French humanities researcher Louis Marin (1984) in an earlier decade evoked notions about the spread of "degenerative utopias" which accompanies the detachment of social communities; as neighbourhood aesthetics are subverted, uneven income growth and economic decline coupled with indifferent nationalist sentiments, contribute to a decline of 
appreciation for locality of place, and a corresponding preferences in favour of universal, homogeneous spaces, a likely response to the increasing fear of crime and prevalence of urban poverty. With growing intensity of urban architecture's purpose to enhance the spectator's profile of lifestyle luxuries rather than sustain living conditions, many overlook the philosophical purism of aestheticians like Adolf Loos (1908):

Changes in the traditional way of building are allowed only if they represent an improvement. Otherwise just follow the traditional, for truth, even if it be hundreds of years old, has a stronger inner bond with us than the lie that walks by our side (University of Washington, n.d.).

Thus far, progress in the field of sustainable built architecture can be traced to a trajectory of industrialisation. Synonyms like 'sustainable', 'eco-friendly and 'green' have since the start of the $21^{\text {st }}$-century been actively spelled out in building construction guidelines, as greater awareness circulated, of the marriage of high performance, energy efficiency and technological applications in designing buildings (Katz, 2003: p.2). However, just as important as plans, are relative factors of conscious usage.

\section{Preston (2007: pp.13-14) states:}

The final product is often the result of compromises. [...] a green solution such as an operable window for ventilation is only truly green when the user remembers to open and close (said) window as needed. Green architectural decisions, in other words, often depend on green minded people understanding and utilising these attributes in order [...] to contribute to sustainability.

Having buildings that are concerned with improving human linkages with natural forms is a part of increasing our inherent appreciation and interaction with the environment. Prof James Steele who teaches at University of Southern California (USC) School of Architecture provides some interesting narratives of the ecological movement over the past century, from earlier designs that reflect cultural identities to material revisioning in the decades accompanying Modernism; leading to the development of complex $21^{\text {st }}$-century's responses to inescapable climatic issues of pollution, global warming and urban decay.

Although inevitably, some soul-searching among builders and planners have led to the search for traditionalist, vernacular approaches such as passive solar ventilation (Fernandes et al, 2015) and thermal comfort systems (Santamouris, 2007), many modern buildings at present also seem to be at cross purposes with advances in social development. The costs of adapting sustainability strategies for high performance buildings could make them less accessible to social segments other than the elite or are otherwise exclusionary towards the economically and technologically disadvantaged.

\subsection{Frank Lloyd Wright: Vanguard in Organic Built Landscapes and Architecture}

Differing perspectives on environmental activism have thus been a key issue that frames literature on architectural and spatial design and some practitioners like Stephen Kellert, Le Corbusier and Taliesin West have earned their placings above others (Hoffman, 1995). Frank Lloyd Wright (1867-1959)'s eminent position derives from spearheading the organic architecture movement, applying "regionally appropriate environmental responses" to accentuate local material usage in constructing, while integrating sustainable values such as energy efficiency to suit climatic needs and lifestyles, resulting in healthier internal environment which harmonises with the natural ambience and vegetation of local surroundings (Craven, 2017). Wright, according to Preston (2007), engaged the classical aesthetics of ages that defines the inheritance of local communities in letting nature determine spatial planning, ensuring the close communing between people and the environment helps connect society to a place, emphasising the aesthetics of regionalism (Frampton, 1983).

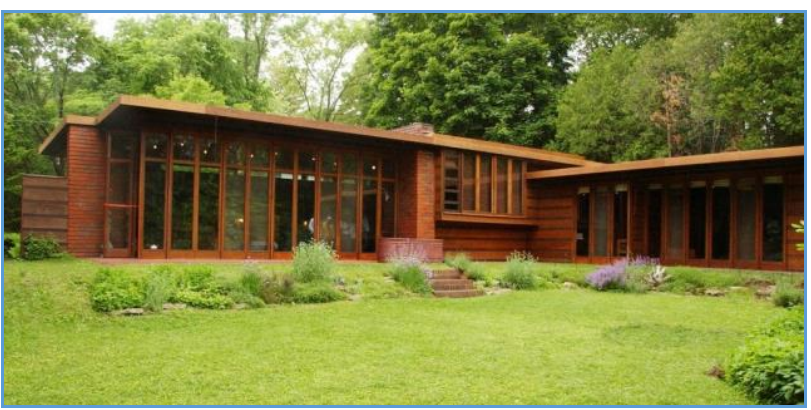

Figure 1. Jacobs I in Madison

Usonia is Wright's poignant tribute to nature, the core inspiration for his visionary philosophy of architectural and landscape designs. Based on Prairie Style aesthetics of North America's vast, flat Midwestern plains, he argued that built form could never be perfectly "finished" spaces, as nature herself does not remain static but carves its own patterns of change (Wright on the Web, 2017). With middle-class American families in mind, the Jacobs I house (Figure 1) built in Madison, Wisconsin in 1937, demonstrates a harmony to the sparse living needs of an economically straitened era. The elegantly low-roofed, single-story home omitted the basement and attic, consolidating internal heating and lighting through passive solar design instead by following the orientation of the sun.

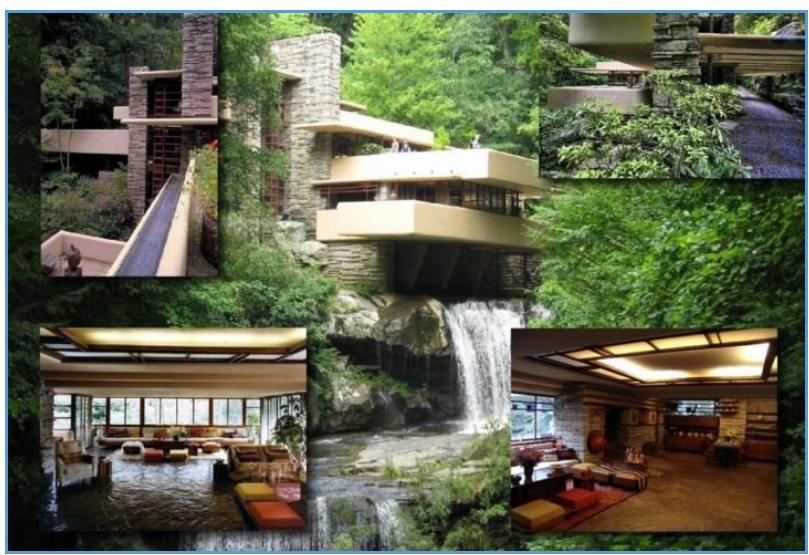

Figure 2. The Fallingwater

Economy of space is seen in the way the kitchen seamlessly nudges into the living area; an open car port accentuates the abundance of ventilation (Sergeant, 1984). This style was pronounced a "modest dignity" and a "sectarian nationalistic" triumph while yet an environmentally friendly home; and was critically lauded and embraced in North America (Blake, 1964). Another Wright masterpiece design which made structural immortality a de rigueur criterion for future architects, topographers and conservationists alike, Fallingwater (Figure 2) perches solemnly over a waterfall nearly 1300 feet above sea 
level, located in the craggy western frontier of Pennsylvania State. Besides integrating shale-and-sandstone terrain, it harmonises the horizontal lines of the building to nature (vertical lines of trees), while exposing the austere aesthetics of local materials such as stone, glass and steel. The American Institute of Architects (AIA) ranks Fallingwater as the $29^{\text {th }}$ out of 150 most endearing North American architectural works (NPR, 2007), reflecting a delicate balance between craft and techne, capturing the sentient spiritual harmony of place and people. This much-romanticised exemplar of built craftsmanship characterises social connections and expresses the way nature submits to the invariable principles of surroundings. Organic built forms are said to induce deeper ecological awareness by strengthening our spirits, cultivating and enriching our positivity (Day, 2014; Hoffman, 1995).

\subsection{Hidden Costs of Eco-Architectural Design}

Arguments on costs can be traced in the theories and thoughts of architects through the ages. In Adolf Loos (1908)'s essay Ornament and Crime, it was noted that decorative ornamentation was a hidden cost: use and often wastage of materials, effort and time to produce objects of adoration and value, hence, leading to the devaluation of labour and the craft itself (University of Washington, n.d.). In the context of modern built forms, bioclimatic architectural principles of optimal energy and resource use give rise to an inevitable economic contradiction: while materials wastage and construction costs are minimised, conventional economic assumption of value creation is based on supplying the marketdriven needs of consumers.

While the financial assessments of properties with eco-designs are quite explicit (Schilling, in Pallagst et al, 2009: pp.149159), the hidden costs calculations are more nuanced. Bioclimatic indicators of healthy built social spaces, as stated in Ecological Design Handbook, are "front-loaded, the work comes at the beginning, the rewards later [...] sustainable design is more a philosophy of building than a building style" (Stitt, 1999).

Studies of passive design effectiveness, including observing the relationships between thermal comfort and human performance have been discussed in length in engineering journals, to demonstrate long run cost-effectiveness of passive strategies such as the reduction of energy bills for building owners (Lawal et al, 2012). Depending on thermal and climatic conditions, vernacular architecture in northern regions adopts design strategies to increase heat gains and with materials and methods which reduces indoor heat losses or insulate for warmth (Frampton, 1983). For southern regions with temperate, arid climates, passive cooling tactics promote natural ventilation through plantings of evergreens and deciduous trees, dispersing solar radiation, heat and light equally, and allowing thicker walls to be built to shade against strong sunlight (Mihaly, 2013; Reed and Lister, 2014).

A range of technologies play enabling roles: these may be applied to evaluate "high performance" sustainability criteria such as green index certifications, manufacture rating, as well as directories of eco-safe products. Metrics can be leveraged and compared, without foregoing the emphasis on safety and health (Pearce and Yong, 2012). In this regard, eco-landscape architect James Wines (in Preston, 2007: p.18) should be noted. $\mathrm{He}$ believes rational principles that address effectiveness of green architecture are important motivators to foster environmental responsibility, but aside from promoting "mechanistic" benefits of thermal glass, photovoltaic cells and green walls, ecological designers should engage stakeholders in seeking more critical input on how to adapt, appropriate as a cost-effective function of green spatial and interior designs (Reed and Lister, 2014).

Marialena Nikolopoulou of the University of Kent School of Architecture cautions designers undertaking eco-architectural projects as ego-trips: "Good designs are where it is not dictated to the individual how they should perceive, operate or feel in the building, but have the flexibility to explore and experience it for themselves" (The Independent, 2016). The environment, in other words, must be "the envelope which contains, provides and sustains the entire economy" (Hawken et al, 1999: p.9). Literature further points to the necessity of preserving urban architecture (e.g. eco-villages) as valuable cultural artefacts, contributing to psychosocial wellbeing of urban communities (Hawken et al, 1999; Wines, 2000). Buildings must be linked by greenways and public access networks, while the management of surrounding landscapes should be a constant concern for urban planners (Schilling in Pallagst et al, 2009; Hartenberger, in Burton, 2015).

To sum, critical regionalism in architecture should be measured for social, environmental and economic impacts other than demonstrating local political aspirations. Sustainable architecture requires $21^{\text {st }}$-century technological applications for design planning; metric tools for safe construction, ecomaterials which meet health standards for installation; thermalresponsive insulation conditions to adapt a building to its immediate environment, and place-making approaches that draws connections between what the environment supplies, what culture expresses, and what human creative potential could add.

\section{METHODOLOGY OF RESEARCH}

To begin the process of critical inquiry for this research, and to provide practical perspectives on green architectural solutions applicable specific to Asian climates, it was decided to analyse several relevant case studies. The case study approach combines underpinning philosophies of art, architecture and design, and is helpful to derive accurate public perceptions of urban design planning. Terranova and Tromble (2017) explain that architectural solutions are often better articulated through understanding its functional and theoretical perspectives in descriptive analyses. An example of the use of case study as a qualitative prescriptive method was Fernandes et al (2015), who confirm the potential of vernacular construction for urban buildings using passive strategies such as the use of glazed balconies as an indoor thermal strategy in different regions of Portugal. The use of case studies enables depth description and comparison of long-term factors as an arguably effective basis to foster architectural vernacularism. This enables field practitioners to understand perceptions of passive design performance in longer timeframes, how they impact users in various regions, and how spatial utilisation changes, the factors which quantitative assessments of short-term field research may miss.

\section{FINDINGS FROM THE CASE STUDIES}

Since built sciences are historically related to human innovation sciences, case methods which embodies the form, content and intents of current practices, improve our material knowledge of 
"bio-architecture", through monitoring the dynamic combination of aesthetic and rationality in pursuit of organic relationships with the environment, and shows how ecosolutions can be integrated for better living ideals in urbanised societies (Terranova and Tromble; 2017: pp.1-9). The case study sections which follow will introduce the two key figures in eco-architectural design practices - Ken Yeang and Kevin Mark Low.

\subsection{Bioclimatic Skyscraper: Ken Yeang}

Skyscraper projects are huge and complicated. Beyond appearance, a deep understanding of the parameters of design sustainability is required to ensure skyscrapers manifest its façade, functionality, aesthetic and structural distinction, while enabling architects to respond courageously and creatively to environmental responsibility challenges. Since its introduction in 1885 in Chicago, skyscrapers have impacted on contemporary urbanism as a potent symbol of powerful corporate dominance and engineering innovation. Sunlight orientation, wind loading, and thermal stress are necessarily to be accounted for in designing high-rise structures (Yeang, 1996: p.162).

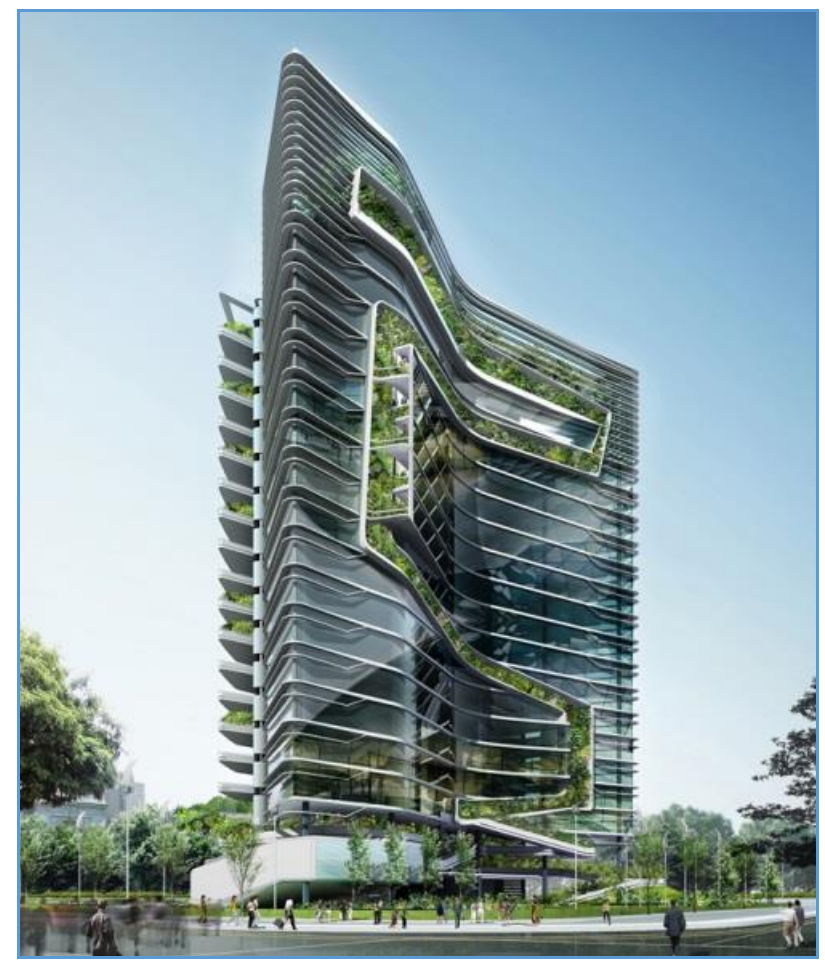

Figure 3. Spire Edge Tower, India

Ken Yeang is a Malaysian eco-architect who developed an environmental approach incorporating bioclimatic techniques in skyscraper architecture, arising from concerns about high-rise buildings' energy usage. The design construction challenge for skyscrapers is centred on its exterior envelope, deciding on the high-efficiency structural materials used, and scaled-down or homogeneous design for tall building facades on all sides. This is a critical factor in Yeang's passive approach as an understanding of variables in the bioclimatic exterior structure to improve users' comfort when occupying interior spaces, while creating suitable micro-climates through optimisation of natural day lighting, sun shading, and natural ventilation (Yeang, 1996). Yeang applies the environmental context on facade treatment, following the sun-paths which are different for each side, ensuring climate-responsiveness, and the overall reduction of energy consumption of the building.

For the design of Spire Edge Tower in Gurgaon India (Figure 3 ), a vertical green wall system was built as the fundamental expression of the "eco-skyscraper" (Hart, 2011). Each level of the 21-storey commercial trade centre is landscaped to enhance spatial greenery and sunlight shading capacity while attaining its biodiversity goals. The design is marked by continuous planting zones all the way to the roof garden, to represent open social spaces which encourage connectivity of people. At the same time, Yeang considers technological aspects of climate response systems such as solar radiation control and low-energy systems as "experimental components leading towards ecological architecture", and advises architectural designers to find alternatives - providing more "benign bio-integration [of techniques] with the environment" (Hart, 2011: p.15).

\subsection{Ethos of Ken Yeang}

Aside from skyscrapers, Yeang's bioclimatic approach is implemented in other projects. The National Library Building (NLB), constructed in 2005 (Figure 4), is considered one of Singapore's most endearing buildings, with a thoroughly modern character that reflects the island nation's "multicultural heritage and its aspirations to be learning nation" (Hart, 2011).

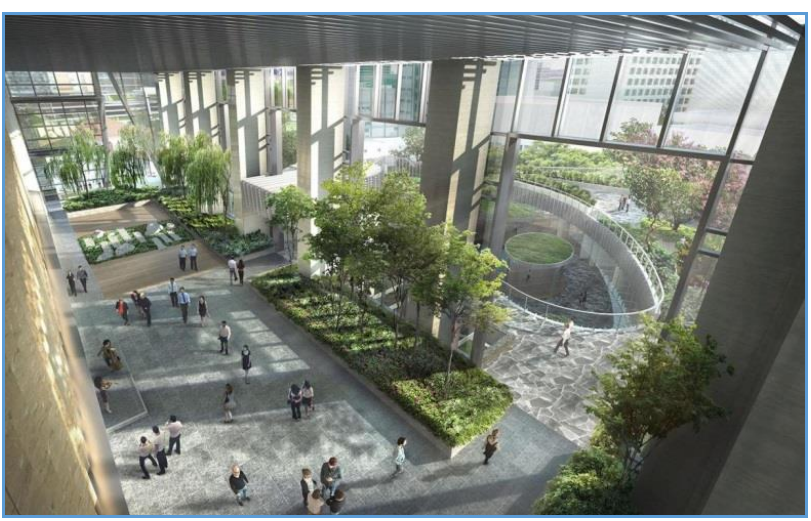

Figure 4. Indoor of National Library Building, Singapore

The energy efficiency index of the building is lower than other typical buildings of similar size. The façade makes use of natural day-lighting for illumination. Designing NLB with its master-plan of hardscape of a cultural plaza (on ground) and soft-scape (a sky garden open to public), the vertical design coalesced with Zaha Hadid's master-plan for another awardwinning tall building project, Solaris Singapore in 2008 (Hart, 2011).

Yeang applied ecological connections through introducing natural atrium ventilation for horizontal and vertical spatial greening such as ramps, terraces, walls, and roof gardens, thus accentuating the building's organic relationship with the city. Yeang's design coup for NLB Singapore is clear testimonial that sustainable architecture design not only reflects in low-cost or low-rise architecture. High-rise buildings may apply sustainability of form just as authentically in its approaches as well.

\subsection{Small Projects: Kevin Mark Low}

Vernacular architecture deals with natural climatic phenomena in traditional ways. Kevin Mark Low is an architect who 
combines bioclimatic theories with architectural designs. His main concern, reducing maintenance cost of buildings by reexamining purpose and using local materials with minimally processed natural bio-finishing, is reflected in his approach for contemporary spatial designs:

"I would rather build economically than lavishly regardless of place, [from my] belief that [I would] ultimately prioritises the architecture of economy over that aesthetic opulence" (Low, 2010).

Locally sourced materials can reduce transportation and shipping costs, leaves a smaller carbon footprint, requiring less maintenance and adaptation to the climate conditions, while strengthening the identities of place and time. While new materials and technologies are preferred as cost-efficient solutions amongst taste-conscious breed of 'starchitects', Low permit authentic elements and the living experience of inhabitants to govern future improvements.

Rather than undertaking skyscrapers for project commissions, Low's works focuses on developing ideas into cultural-infused interior spaces for residential and non-commercial projects: "[...] experimentation works more effectively when performed at a small scale; similar issues become difficult to control at increasing levels of size" (Low, 2010).

\subsection{Ethos of Kevin Mark Low}

While Yeang works in macro master-planning, Low works in micro details of the space, it is the deep meaning of his "small projects". The narrative of Low's projects begins from the front gate, the first step into the building, even the mailbox design, and flowing into its main spaces, as the daily activities are worked in prominent spaces such as stairs and service areas such as kitchen and laundry, with design features and installations such as water pipes and screws exposed to present their aesthetic, reflecting naturalistic design process as aesthetically more superior than the final look of the product.

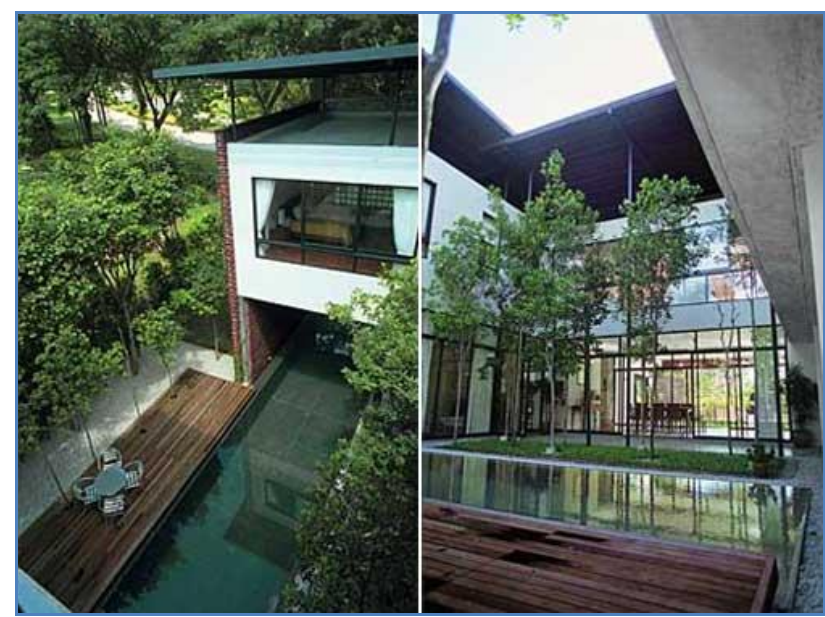

Figure 5. Safari Roof House

Low also considers bioclimatic responses to heat, cold, moisture, function, maintenance, and surface performance (Low, 2010). Safari Roof House (Figure 5), located in a suburban area of Malaysia and surrounded by a golfing course, was created as a garden hideaway, revealing the inhabitants' personalities while resisting conventional design methods. The identity of its location bespeaks stories of elements, the wind, water, and sun, before showing its main techne: the heat sink in the form of a courtyard lined densely with trees. Raw cement vents, eastward facing for direct exposure to the morning sun, are aged to counter the ravages of the humid tropics.

Clearly, Low's conceptual designing process follows the new vernacular paradigm, engaging his talents to articulate an ingenious aesthetic of architecture which starts with nature as determinant of place, instead of designing spatially based around the final architecture.

\section{DISCUSSION AND INTERPRETATIVE PHENOMENOLOGICAL ANALYSIS}

As discussed in literature, theoretical ideas about sustainable architecture are developed as a continuum study of human development, embracing three factors for place-specific responses, namely tradition, technology and urbanism (Steele, 2005).

The current research will attempt to provide a justification for qualitative method as evidence which promotes qualitative analysis and observation of eco-sustainable aspects that might reveal success or failure of the case studies.

Day (2002: p.16) argues that sustainable place-making through architecture should not seek to impose ambitious design plans of individual designers, but focuses on creating places for people "building upon what is already there ... the substance and $[\ldots]$ spirit ... already present in a place since every idea for a building is inspired by the future".

\subsection{Adapting the Vernacular into Modern Architecture}

The critical necessity of finer-grained details for naturalistic built forms can be seen in the works of Yeang which combines urban vernacularism to enables eco-architectural works to be integrated into the global economic development, without losing distinct representation of local place-making and heritage, with the added honour badge of contemporary ecological sensibilities to address resource consumption, materials costs and wastage.

High levels of climate damage attributable to building construction should not be a hidden agenda among developers: society must demand for more sustainable strategies and socially responsible practices to replace once-degenerative built legacies. Modern bioclimatic skyscrapers may seem an incongruous but necessary investment that exist due to their perceived scale of economic importance; their fruition could serve as clues in the preservation of traditional vernacular precedents such as resources, cultural lifestyles and social identities of urban architecture. Yeang (1996: p.236) sums it concisely: "The identity of the skyscraper should reflect the culture and climate within which it is placed".

On the other hand, combining the new and vernacular, as Low and Wright did, shows the possible strategies to create architecture that respects and characterises the specific environmental conditions and local aesthetics. Urban vernacular forms have evolved from initial anti-Modernism strategies into sustainable, $21^{\text {st }}$-century, built innovation. Advances in passive cooling technologies, heat dispersal systems and ecological materials emphasise assurance on thermal comfort conditions, optimal functionality of green infrastructure through costs, waste and energy reduction (Hawken at al 1999: pp.87-88). These are vital interlinked 
aspects which augment place-making sentiments bearing positive economic, social and spiritual outcomes.

Standing in the pathway of unprecedented, global environmental events and climate changes ensuing from urban population explosion and overconsumption, eco-architects must seek solutions to the list of factors that cancels out the financial benefits of green buildings in the longer term (Kats, 2003). The 'urban heat island' phenomenon and its effects, for instance, have been widely studied by environmentalists. As cost increases of energy demands and water consumption are expected in the coming years, urban heat islands precipitate the need for impact-ready, sustainable buildings to overcome floods and landslides arising from temperature anomalies.

\section{CONCLUSION}

Conceptual theories of humanistic disciplines provide current generations of architects and planners a definitive understanding of the essence of good sustainability practices in architecture over the past decades (Fernandes et al, 2015; Hoffman, 1978). As a study of architectural regionalism, the practice of eco-design is acknowledged to be a resourceful, sustainable and creative bioclimatic response for urban built infrastructure development. Clearly, researchers need to future-proof their understanding and how new solutions would impact architectural philosophies, building processes and methodologies. Generating grounded theories via qualitative methodologies enables industry practitioners to better position their ethos of sustainability awareness among an increasingly discerning public.

This is achieved through understanding materiality, available local resources, built orientation, passive ventilation, energysaving techniques, façade views of exterior and interior, and workmanship which captures the moods and ebbs of social topography, all which are essential attributes of sustainable architecture (Wood, 2008).

This brief review of two architects found co-opting strategies of architectural design research and cultural experience as the basis of continual development of built practices. Understanding and applying nature's organic frames is a crucial component of achieving eco-design outcomes.

Essentially, the importance of qualitative observation of local elements such as cultural behaviour, resource availability and management and effective spatial planning is affirmed, as they enable architectural designers to improve the quality of living spaces. Additionally, nationalism and environmentalism play complementary roles in the designing and expressing the roots of our local identity and spirituality (Day, 2002), and climateresponsive building designs play a key role in successfully mainstreaming sustainable urban architecture as worthy social and place-making identities

For architectural design to orientate social attitudes towards ecological benefits, substantial, critical studies are required. The thrust forward is the evaluation of benefits beyond economic yields of commercial built designs (Hartenberger, in Burton, 2015). As sustainability debates spiral to new heights of arguments and counter arguments, each critique and advocate substantiating their views and claims of importance, geographical, economic, social, psychological and aesthetic aspects are important underlying motivators for stakeholders (Wines, in Preston, 2015: p.18). Where $21^{\text {st }}$-century architectural design tend to accentuate the economic benefits of technological adoption, evidence presented in this paper proves that among Asian bio-climatic architectural designers, compelling urban architecture is indicated by sustainable and creative approaches, and both can be further fostered through principles and strategies which are founded and grounded on nature.

\section{REFERENCES}

Blake, P., 1964. Frank Lloyd Wright: Architecture and Space. London: Penguin Books.

Burton, S., 2015. Sustainable Retrofitting of Commercial Buildings. Abingdon: Routledge.

Craven, J., 2017, March 26. 'What Is Organic Architecture? Nature as a Tool'. ThoughtCo. Retrieved from:

https://www.thoughtco.com/organic-architecture-nature-as-a-tool178199

Day, C., 2002. Spirit and Place. Oxford: Architectural Press.

Day, C., 2004. Places of the Soul: Architecture and Environmental Design as Healing Art. $2^{\text {nd }}$ ed. Oxford: Architectural Press.

Day, C., 2014. Places of the Soul: Architecture and Environmental Design as Healing Art. $3^{\text {rd }}$ ed. Oxford: Architectural Press.

Fernandes, J., Pimenta, C., Mateus, R., Silva, S.M. and Braganca, L., 2015. 'Contribution of Portuguese Vernacular Building Strategies to Indoor Thermal Comfort and Occupants' Perception'. Buildings, 5: pp.1242-1264.

Frampton, K., 1983. 'Towards A Critical Regionalism: Six Points for an Architecture of Resistance', in H. Foster (ed.) Essays on Postmodern Culture. Washington: Bay Press.

Hart, S., 2011. Eco Architecture: The Work of Ken Yeang. UK: John Wiley \& Sons, Ltd.

Hawken, P., Lovins, A.B. and Lovins, L.H., 1999. Natural Capitalism: Creating the Next Industrial Revolution. Boston: Little Brown \& Co.

Hoffmann, D., 1978. Frank Lloyd Wright's Fallingwater: The House and Its History. $2^{\text {nd }}$ revised ed. New York: Dover Publications, Inc.

Hoffman D., 1995. Understanding Frank Lloyd Wright's Architecture. New York: Dover, Inc.

Kats, G., 2003. The Costs and Financial Benefits of Green Buildings. [Report to California Sustainable Building Task Force] October: Sacramento, CA.

Lawal, A.F., Akinbami, J.F.K. and Akinpade, J.A., 2012. 'Assessing effectiveness of utilisation of passive design parameters on active energy consumption in public buildings in warm-humid climate'. Journal of Civil Engineering and Construction Technology, 3(4): pp.140-47.

Low, K.M., 2010. Small Projects. Reyes Stations, CA: ORO Group.

Marin, L., 1984. Utopics: Spatial Play. [Transl. R.A. Vollrath] London: Humanities Press International/Macmillan.

Mihaly, W., 2013. Small Projects: Kevin Mark Low. Architecture AU. Retrieved from:

https://architectureau.com/articles/kevin-mark-low-god-of-small-things/ 
ISPRS Annals of the Photogrammetry, Remote Sensing and Spatial Information Sciences, Volume IV-4/W9, 2019 4th International Conference on Smart Data and Smart Cities, 1-3 October 2019, Kuala Lumpur, Malaysia

NPR, 2007. America's Favourite Architecture. American Institute of Architects 'AIA150' [Poll]. Retrieved from:

http://www.npr.org/documents/2007/feb/buildings/150buildings.pdf

Pallagst, K., 2009. The Future of Shrinking Cities - Problems, Patterns and Strategies of Urban Transformation in a Global Context. [Monograph] Berkeley CA: University of California Institute of Urban and Regional Development.

Pearce, A. and Yong, H.A., 2012. Sustainable Buildings and Infrastructure: Paths to the Future. Abingdon: Routledge.

Preston, J.C., 2007 Connecting with Nature: Building a Spirit of Sustainability in Architectural Design. [Master Thesis] Tucson, Arizona: University of Arizona Department of Architecture.

Reed, C. and Lister, N.M., 2014, April 14. 'Ecology and Design: Parallel Genealogies'. Places [Online Journal]. Retrieved from: https://placesjournal.org/article/ecology-and-design-parallelgenealogies/

Santamouris, M., ed., 2007. Buildings, Energy, Solar Technology: Advances in Passive Cooling. London: Earthscan.

Stitt, F.A., 1999. Ecological Design Handbook: Sustainable Strategies for architecture, Landscape Architecture, Interior Design, and Planning. New York: McGraw-Hill.

Steele, J., 2005. Ecological Architecture: A Critical History. London: Thames \& Hudson.

Terranova, C.N. and Tromble, M. eds., 2017. The Routledge Companion to Biology in Art and Architecture. New York, NY: Routledge.

The Independent, 2016, April 19. How Architecture Uses Space, Light and Material to Affect Your Mood. Retrieved from:

http://www.independent.co.uk/life-style/design/how-architecture-usesspace-light-and-material-to-affect-your-mood-american-institutearchitects-a6985986.htm

University of Washington, n.d. Adolf Loos: Ornament and Crime, 1908. Retrieved from:

http://depts.washington.edu/vienna/documents/Loos/Loos_Ornament.ht $\mathrm{m}$

Wines, J., 2000. Green Architecture. New York: Taschen Books.

Wood, A., 2008. Green or Grey? The Aesthetics of Tall Building Sustainability [Research Paper] Dubai: Council on Tall Buildings and Urban Habitat (CTBUH) 8th World Congress. Retrieved from: http://global.ctbuh.org/resources/papers/download/1313-green-or-greythe-aesthetics-of-tall-building-sustainability.pdf

Wright on the Web, 2017. Prairie Style. Retrieved from: http://www.wrightontheweb.net/his-works/prairie-style/

Yeang, K., 1996. The Skyscraper Bioclimatically Considered: A Design Primer. England: Wiley-Academy.

\section{Images Credit}

Figure 1: Craven, J., 2017. What Is a Usonian House? Retrieved from: https://www.thoughtco.com/usonian-style-home-frank-lloydwright-177787

Figure 2: Craven, J. , 2017. 1935: Fallingwater. Retrieved from: https://www.thoughtco.com/frank-lloyd-wright-portfolio-selectedarchitecture-4065231

Figure 3: Baijak, M., 2013. Top 5 Ken Yeang Green Design We'd Love to See in Melbourne. Retrieved from https://urbanmelbourne.info/sustainabilityenvironment/2013/08/05/top-5-ken-yeang-green-designs-wed-love-tosee-in-melbourne

Figure 4: OpenBuildings, 2012. Singapore National Library. Retrieved from: http://openbuildings.com/buildings/singaporenational-library-profile-43211

Figure 5: Safari Roof House. Small Projects. Retrieved from: http://architecture512.blogspot.com/2009/05/kevin-low-ventblockhouse.html 